\title{
Elaboration and Characterization of Bioactive Films Obtained from the Incorporation of Cashew Nut Shell Liquid into a Matrix of Sodium Alginate
}

\author{
Larruama Vasconcelos ${ }^{1, *}$, Marthyna de Souza ${ }^{1, *} * \mathbb{C}$, Juliana de Oliveira ${ }^{1}$, Edson Silva Filho ${ }^{2}{ }^{\mathbb{D}}$, André Silva ${ }^{1}$, \\ Selma Elaine Mazzetto ${ }^{3}$, Elzânia Sales Pereira ${ }^{4}$, Ronaldo Lopes Oliveira ${ }^{5}$ and Leilson Bezerra ${ }^{1, *(1)}$
}

1 Department of Animal Science, Animal Health and Science Graduate, Federal University of Campina Grande, Avenida Universitária, s/n-Jatobá, Patos 58708110, Brazil; juli.foo@gmail.com (J.d.O.); andre.leandro@ufcg.edu.br (A.S.)

2 Department of Animal Science, Federal University of Piaui, Ininga, s/n, Teresina 64049550, Brazil; edsonfilho@ufpi.edu.br

3 Department of Organic and Inorganic Chemistry, Federal University of Ceará, Contorno Street, Fortaleza 60451970, Brazil; selma@ufc.br

4 Department of Animal Science, Federal University of Ceará, Av. Mister Hull, Fortaleza 60356000, Brazil; elzania@ufc.br

5 Department of Animal Science, Federal University of Bahia, Av. Adhemar de Barros, 500, Ondina, Salvador 40170110, Brazil; ronaldooliveira@ufba.br

check for updates

Citation: Vasconcelos, L.; de Souza, M.; de Oliveira, J.; Silva Filho, E.; Silva, A.; Mazzetto, S.E.; Pereira, E.S.; Oliveira, R.L.; Bezerra, L. Elaboration and Characterization of Bioactive Films Obtained from the Incorporation of Cashew Nut Shell Liquid into a Matrix of Sodium Alginate. Antioxidants 2021, 10, 1378. https://doi.org/10.3390/ antiox10091378

Academic Editor: María Pilar Almajano Pablos

Received: 5 August 2021

Accepted: 24 August 2021

Published: 28 August 2021

Publisher's Note: MDPI stays neutral with regard to jurisdictional claims in published maps and institutional affiliations.

Copyright: () 2021 by the authors. Licensee MDPI, Basel, Switzerland. This article is an open access article distributed under the terms and conditions of the Creative Commons Attribution (CC BY) license (https:// creativecommons.org/licenses/by/ $4.0 /)$.
* Correspondence: larruama_priscylla@hotmail.com (L.V.); marthynapessoa2@gmail.com (M.d.S.); leilson@ufpi.edu.br (L.B.)

Abstract: The objective of this work was to obtain and characterize sodium alginate-based biopolymer films with the addition of cashew nut shell liquid (CNSL). The study employed a completely randomized design, including $0 \%, 0.5 \%, 1 \%$, and $1.5 \%$ inclusion of CNSL. Uniform formation of the films was observed, and the addition of CNSL provided better thermal resistance than did the treatment without inclusion, while the addition of CNSL reduced the homogeneity of the microstructure, especially for the $1.5 \%$ inclusion level. The permeability of the film increased as the level of CNSL increased, especially in response to the concentrations of $1 \%$ and $1.5 \%$, and no significant difference in permeability was observed between these treatments. The tensile strength decreased proportionally as a function of the addition of CNSL, as its inclusion increased the elasticity and elongation of the films. In addition, the films with CNSL demonstrated strong antioxidant activity and discrete antimicrobial activity, and ecotoxicity analysis showed that the levels of CNSL tested and the films produced were nontoxic. Thus, these films are promising and self-sustainable alternatives for the agrifood industry.

Keywords: Anacardium occidentale; edible film; bioactive packaging; antioxidant film; sustainability

\section{Introduction}

Food packaging plays a fundamental role both in food preservation and throughout its distribution chain [1]. The main objective is to separate food from the circulating environment, decreasing contact with various conditions leading to deterioration, including microorganisms, oxygen, $\mathrm{pH}$, water vapor, and odious flavors, as well as preventing losses of important compounds such as volatiles; in short, packaging protects the food from contaminants and consequently prolongs the useful life of the food [2]. In this context, the material used in the manufacturing and manipulation of packaging is very important in preserving the quality of food and delaying its decomposition rate [3].

Much of the food packaging currently used was developed using petroleum-based polymers and plastics, in view of the lower financial cost, high mechanical strength and rigidity of these materials, as well as their versatility of shapes and heat sealing capacity. 
As a result, these materials occupy $37 \%$ of the total market for food packaging materials. However, this type of packaging is nonrenewable and nonbiodegradable and is responsible for an increase in environmental pollution; as such petroleum-based polymers and plastics as environmentally are considered unfavorable $[4,5]$.

Thus, the increase in research involving eco-friendly packaging, such as the production of biodegradable films, has recently gained greater traction [6]. This is because these films can replace plastic bags used on food products because they have a lifetime of few minutes to hours, while the plastics stay in the environment for decades [7].

Films obtained from biopolymeric matrices have been gaining prominence since they are biodegradable and can often delay the deterioration of food [8]. Different biopolymers can be used for the fabrication of these films, including polysaccharides, which are common materials recently used to obtain films with biodegradability properties [9]. Among these biodegradable films, alginate has been widely used since films based on this biopolymer have excellent barrier properties against oxygen, carbon dioxide, and lipids, in addition to excellent mechanical characteristics, including tensile strength and ductility [10].

Nevertheless, unfortunately, there is no natural polymer that, individually, is capable of providing all the desired properties for film formation, namely, moisture barrier properties, mechanical and thermal properties, ability to form coatings and gelling properties, water-solubility, odorlessness, tastelessness, colorlessness, translucence, flexibility, and possessing antimicrobial activity and antioxidant activity while preserving food additives such as antioxidants, dyes, and flavors, among others. Thus, it is necessary to select and integrate the ingredients of films so that they act synergistically to obtain films with all the properties consistent with their intended use [10].

Therefore, one of the recent focuses in the fabrication of films is to increase their functionality, adding characteristics such as antioxidant and/or antimicrobial activity, by incorporating components with these properties, for instance, functional oils that can increase the stability of food during storage, preventing food deterioration by delaying lipid oxidation, as well as the growth of pathogenic microorganisms [11], especially in easily perishable foods.

Researchers consider the importance of antioxidants derived from low-cost renewable sources, for example, cashew nut shell liquid (CNSL), which is a cheap oil derived from byproducts of the cashew (Anacardium occidentale L.) and composed mainly of anacardic acid $(60 \%$ to $65 \%)$ [12]. For the removal of the nut, the cashew is submitted to an industrial process through submission to high temperatures, in which anacardic acid undergoes a decarboxylation reaction, generating technical CNSL, composed mainly of cardanol (60\% to $65 \%)$, cardol (15\% to $20 \%$ ), polymeric constituents (10\%) and 2-methyl cardol (traces). This product of the high-temperature treatment presents as a dark (almost black), viscous liquid with a characteristic odor [13]. CNSL, in addition to being a renewable, biodegradable, inexpensive source in abundance in Brazil, is extremely rich in phenolic and bioactive compounds, thus presenting powerful antioxidant activity, especially due to the high content of cardanol present in technical CNSL, in addition to antimicrobial activity [14]. Thus, CNSL exhibits desirable essential characteristics for use as an additive in the production of films aimed at slowing the lipid oxidation process and consequently increasing the shelf life of food because the incorporated active agents define the functionality of packaging materials [15].

In this context, considering the environmental appeal of CNSL as the main focus of this study, as well as the importance of packaging, the sustainability of CNSL, and its potential to increase the shelf life of perishable foods, the present research aimed to develop and characterize bioactive films based on sodium alginate enriched with CNSL in order to identify their potential use in the agrifood industry as a possible substitute for nondegradable food packaging. 


\section{Materials and Methods}

\subsection{Material}

Sodium alginate was purchased from Dinâmica Química Contemporânea LTDA (Indaiatuba, São Paulo, Brazil). The technical CNSL (containing 84.4\% cardanol and 15.6\% cardol) used was supplied by Amêndoas do Brasil LTDA (Fortaleza, Brazil). Brain heart infusion (BHI) agar and solvents were purchased from Merck (Darmstadt, Germany). Diammonium 2,2'-Azino-bis(3-ethylbenzothiazoline-6-sulfonate) (ABTS) and 2,2-Diphenyl1-picryhydrazyl (DPPH) were purchased from Sigma-Aldrich (St. Louis, MO, USA). All chemicals were analytical grade.

\subsection{Elaboration of the Biopolymer Films}

Sodium alginate-based films were developed based on Oussalah et al. [16]. Initially, a sodium alginate solution was obtained at a concentration of $3 \%(w / w)$. Subsequently, glycerol and Tween 80 were added to the sodium alginate solution at concentrations of 2 and $0.5 \%(w / w$, based on the alginate solution mass). The mixture was then heated to $70{ }^{\circ} \mathrm{C}$ on a hot plate and shaken with a glass rod for $1 \mathrm{~h}$ for total homogenization of the filmogenic solution (FS). Then, technical CNSL was added to the filmogenic solution at the respective inclusion levels $(0 \%, 0.5 \%, 1.0 \%$, and $1.5 \%(w / w$, based on FS mass $))$, remaining under manual stirring (glass rod) for 20 min until total homogenization.

Finally, the mixture was placed into disposable Petri dishes $(90 \times 15 \mathrm{~mm})$, properly identified, and dried in an air circulation oven at $45^{\circ} \mathrm{C}$ for $24 \mathrm{~h}$. After drying, the films were removed using tweezers, wrapped in aluminum foil, and stored in polyethylene Ziploc bags at $25^{\circ} \mathrm{C}$ and $54 \%$ relative humidity [obtained using a saturated solution of $\left.\mathrm{Mg}\left(\mathrm{NO}_{3}\right)_{2} \cdot 6 \mathrm{H}_{2} \mathrm{O}\right]$.

\subsection{Characterization of Films}

2.3.1. Thermogravimetric Analysis (TGA) and Differential Scanning Calorimetry (DSC)

The thermogravimetric and DSC curves were obtained via a simultaneous thermal analyzer (SDT Q600 V20.9 Build 20), with a $\mathrm{N}_{2}$ atmosphere (flow of $100 \mathrm{~mL} / \mathrm{min}$ and heating of $10{ }^{\circ} \mathrm{C} / \mathrm{min}$ ), from 30 to $600{ }^{\circ} \mathrm{C}$ (30 to $300{ }^{\circ} \mathrm{C}$ was considered for DSC curves), using a platinum crucible containing $8 \mathrm{mg} \pm 0.0001 \mathrm{~g}$ of sample.

The parameters extracted from the thermogravimetric and DSC curves were the initial thermal degradation temperature $-\mathrm{T}_{\text {onset }}$ (extrapolated temperature at the point of intersection of the starting-mass baseline and the tangent to the thermogravimetric curve at the point of maximum declivity) and thermal degradation peak temperature, respectively, using OriginPro 8.

\subsubsection{Color and Opacity}

Five measurements were randomly performed on each $90 \times 15 \mathrm{~mm}$ size film replica, and the test was conducted in triplicate, resulting in fifteen readings for each film studied. The average of the measurements was considered. A digital colorimeter (CR 400; Minolta, Japan) calibrated with the white standard illuminant $\mathrm{C}$ was used to measure color and opacity. The parameters determined were luminosity or $\mathrm{L}^{*}\left(\mathrm{~L}^{*}=0[\mathrm{black}]\right.$ and $\mathrm{L}^{*}=100$ [white] $)$, red or $\mathrm{a}^{*}\left(-\mathrm{a}^{*}=\right.$ green and $+\mathrm{a}^{*}=$ red $)$, and yellow or $\mathrm{b}^{*}\left(-\mathrm{b}^{*}=\mathrm{blue}\right.$ and $+b^{*}=$ yellow). The saturation index or chroma $\left(C^{*}\right)$ was calculated according to the following formula: $\left(a^{*} 2+b^{*} 2\right) 0.5$. [17]. The opacity $(Y)$ was determined using the following equation: $\mathrm{Y}(\%)=(\mathrm{Yp} / \mathrm{Yb}) \times 100$, where $(\mathrm{Yp})$ is the opacity of the coating in the black pattern and $(\mathrm{Yb})$ is the relative opacity in the white pattern [8].

\subsubsection{Morphology of the Films}

The morphology was analyzed by scanning electron microscopy (SEM) using a TESCAN VEGA3 microscope (Brno, Czech Republic), corresponding to a tungsten thermionic emission system suitable for high and low vacuum operation, with an accelerating voltage 
from $5 \mathrm{kV}$. Before obtaining the micrographs, samples of all films $(10 \times 10 \mathrm{~mm})$ were first metalized with a thin layer of gold.

\subsubsection{Thickness}

A digital micrometer (Digimess, São Paulo, Brazil) was used to study the thickness of the films, measured at five different points of each film, chosen at random, in triplicate, thus totaling fifteen readings for each type of film, after the measurement of color and opacity, using the same $90 \times 15 \mathrm{~mm}$ samples.

\subsubsection{Water Vapor Permeability}

Water vapor permeability (WVP) was determined by gravimetric analysis according to Souza et al. [8]. Initially, the top of a permeation cell with distilled water (relative humidity of $100 \%$, steam pressure of $2337 \mathrm{~Pa}$ and $20^{\circ} \mathrm{C}$ ) was sealed with the film and then placed in a desiccator with silica at $25^{\circ} \mathrm{C}, 0 \%$ relative humidity, and a water vapor pressure of $0 \mathrm{~Pa}$. Eventually, the cells were weighed every $2 \mathrm{~h}$ for $10 \mathrm{~h}$. Linear regression was used to obtain the inclination of the loss of mass versus time. WVP was calculated as follows: $\mathrm{WVP}=(\mathrm{WVTR} \times \mathrm{T}) / \Delta \mathrm{P}$, where WVTR is the rate of water vapor transmission $\left(\mathrm{g} / \mathrm{m}^{2} \cdot \mathrm{s}\right), \mathrm{T}$ is the average thickness $(\mathrm{m})$, and $\Delta \mathrm{P}$ is the partial difference of water vapor pressures $(\mathrm{Pa})$ on both sides of the film.

\subsubsection{Mechanical Properties}

The tests for maximum tensile strength, modulus of elasticity, and elongation at break were performed using a Universal Testing Machine (EMIC-DL-500) according to ASTM D882-12 standards (Standard Test Method for Tensile Properties of Thin Plastic Sheeting) [18]. The initial separation of the claws was $10 \mathrm{~mm}$, and the traction speed was $5 \mathrm{~mm} / \mathrm{min}$. Software was used for data collection regarding the stress-strain curve $(\mathrm{MPa})$ versus deformation (\%). Young's modulus for the samples was determined from the tangent of the elastic region of the stress-strain $\times$ deformation curves. Elongation values at breakage were estimated considering the ratio of final length at the point of the sample breakage to the initial length of a sample $(10 \mathrm{~mm})$ and expressed in $\%$.

Ten repetitions were conducted for each sample with a length of $50 \mathrm{~mm}$ and a width of $10 \mathrm{~mm}$. Before the analyses, the samples were maintained for 2 days at $25^{\circ} \mathrm{C}$ and $50 \%$ relative humidity.

\subsubsection{Antimicrobial Activity of the CNSL}

Strains of Salmonella typhimurium (ATCC 10028), Listeria monocytogenes (ATCC 7644), Pseudomonas aeruginosa (ATCC 8626), Staphylococcus aureus (ATCC 6538), Bacillus cereus (ATCC 14579), and Escherichia coli (ATCC 8739) were cultivated on brain heart infusion (BHI) agar. After incubation, the colonies of each lineage were aseptically placed into a sterile saline solution $(\mathrm{NaCl} 0.85 \%)$; a value of 0.5 on the McFarland scale $(106 \mathrm{UFC} / \mathrm{mL})$ was used to standardize the turbidity of the solutions.

The minimum inhibitory concentration (MIC) and the minimum bactericidal concentration (MBC) of CNSL were determined according to the Clinical and Laboratory Standards Institute [19] by the microdilution method in a 96-well microplate with concentrations ranging from 2 to $1024 \mu \mathrm{g} / \mathrm{mL}$ by serial dilutions. Then, $100 \mu \mathrm{L}$ of BHI 10 broth (106 UFC/mL of each strain) was added to each well. A rotary shaker (150 rpm) was used to incubate the microorganisms at $37^{\circ} \mathrm{C}$ for $24 \mathrm{~h}$, and then aliquots of the wells without turbidity were transferred to Petri dishes with agar BHI medium and incubated at $37^{\circ} \mathrm{C}$ for $24 \mathrm{~h}$. The MBC was classified as the lowest concentration in which any microbial growth was not observed after the culture. The MIC was considered the highest concentration where turbidity in liquid medium was not observed, but growth was observed after cultivation in solid medium. Azithromycin and sterile saline solution were used as positive and negative controls, respectively. 


\subsubsection{Antibacterial Activity of the Films-Agar Well Diffusion Method}

The antibacterial activity of alginate films with and without CNSL was evaluated using the agar well diffusion method [8].

The sowing of the standard inoculum ( 0.5 on the McFarland scale) was carried out in the form of a carpet on the surface of Petri dishes with half BHI agar using a Drigalski spatula. Then, $5.0 \mathrm{~mm}$ diameter wells were made on each plate and were filled with $20 \mu \mathrm{L}$ of each filmogenic solution with different concentrations of CNSL. As positive and negative controls, azithromycin $(1028 \mu \mathrm{g} / \mathrm{mL})$ and autoclaved distilled water were used, respectively. The incubation conditions of the inoculated plates were $37^{\circ} \mathrm{C}$ for $24 \mathrm{~h}$. The diameter of the growth inhibition zone around the well (measured in triplicate) was the parameter used to evaluate the antibacterial activity.

\subsubsection{Determination of Antioxidant Activity of CNSL}

The methods of 2,2-diphenyl-1-picrylhydrazyl radical (DPPH), 2,2'-azino-bis3-ethylbenzothiazoline-6-sulfonic acid (ABTS) and total antioxidant capacity were performed to investigate the antioxidant activity of CNSL. The analyses were conducted in triplicate, and the percentage of the removed DPPH was used to determine inhibition activities [19]. The standard used was Trolox ${ }^{\circledR}$ (A vitamin E analog). The percentage of inhibition ( $\mathrm{I} \%$ ) was determined by Equation (1):

$$
\mathrm{I} \%=[(\mathrm{Ac}-\mathrm{As}) /(\mathrm{Ac})] \times 100
$$

where Ac is the control absorbance and As is the sample absorbance.

All tests were performed in triplicate. The IC50 of DPPH was determined by linear regression of the percentage of remaining DPPH compared to the concentration of the sample.

The antioxidant activity of CNSL by the ABTS test was determined considering the cationic chromophore radical from ABTS oxidation [20]. The measurements were performed in triplicate, and the percentage of the removed ABTS was used to calculate the inhibition activity. The standard used was Trolox ${ }^{\circledR}$ (a vitamin E analog). The percentage of inhibition ( $\mathrm{I} \%$ ) was determined as demonstrated previously. All the tests were performed in triplicate. The IC50 of ABTS was determined by linear regression of the percentage of remaining ABTS compared to the concentration of the sample.

The phosphomolybdenum method was used to investigate the total antioxidant capacity [21]. The assay was conducted considering the reduction in molybdenum +6 to molybdenum +5 by the sample and posterior generation of a greenish phosphate/molybdenum +5 complex. Tubes with both samples and reagents $(0.6 \mathrm{M}$ sulfuric acid, $28 \mathrm{mM}$ sodium phosphate, and $4 \mathrm{mM}$ ammonium molybdate) were incubated at $100{ }^{\circ} \mathrm{C}$ for $90 \mathrm{~min}$. Subsequently, the absorbance of each solution was read at $695 \mathrm{~nm}$ against a blank solution. The reference used was ascorbic acid. The total antioxidant capacity ( $\mathrm{I} \%$ ) was determined using the I\% equation demonstrated previously. All tests were performed in triplicate. The IC50 of TAC was determined by comparing the regression activity of the coating to the concentration of the sample.

\subsubsection{Determination of the Antioxidant Activity of the Films}

For the evaluation of the antioxidant activity of the biofilms, the method of capture of the DPPH radical (2,2-Diphenyl-1-picrylhydrazyl) was used from the adapted methodology of Blois [20] according to Souza et al. [8]. Rectangular samples of each film (20 mg) were transferred to tubes with $1 \mathrm{~mL}$ of DPPH methanolic solution $(60 \mu \mathrm{M})$, and the mixture was then gently stirred for $30 \mathrm{~min}$ at room temperature $\left(25^{\circ} \mathrm{C}\right)$ and protected from light. Tubes containing only the DPPH solution were used as controls. Subsequently, $200 \mu \mathrm{L}$ of the solution was placed into 96-well plates, and the absorbance was read at $515 \mathrm{~nm}$ (ELISA reader, Bio-Rad Laboratories Hercules, CA, USA) [22]. The free radical (\%) elimination by the sample was determined by Equation (2): 
DPPH elimination capacity $=($ Abs515control - Abs515sample $) /$ Abs515control $\times 100$

where Abs515sample is related to the absorbance of the tubes with the alginate films with or without CNSL and Abs515control is related to the absorbance of the control tubes. All determinations were performed in triplicate, and the results are expressed as the mean \pm standard deviation.

\subsubsection{Toxicity Test}

The toxicity test of CNSL on Artemia salina was carried out according to Meyer et al. [23] using a solution with sea salt at $30 \mathrm{~g} / \mathrm{L}$. A $0.1 \mathrm{~mol} / \mathrm{L} \mathrm{NaOH}$ solution was used to adjust the $\mathrm{pH}$ between 8.0 and 9.0, which was also used for hatching the eggs of Artemia salina and in the preparation of the other solutions by dilution. The eggs were put in to hatch in saline solution for $48 \mathrm{~h}$ under aeration at room temperature $\left(25^{\circ} \mathrm{C}\right)$. Then, approximately 10 larvae of Artemia salina were placed into tubes with saline solution and samples with CNSL at 10, $100,500,1000$, and $1500 \mathrm{ppm}$ and crude extract of the hydrolate. The test was performed in triplicate, and the counting of dead and alive animals was performed after $24 \mathrm{~h}$.

A simple linear equation was adjusted to the data on the percentage of dead Artemia salina larvae in relation to the increased CNSL concentration, which was used to estimate the concentration of extract responsible for killing $50 \%$ of the larvae. A graphic analysis method was used to obtain the LD50 (lethal dose of extract for $50 \%$ of the population). The test was accompanied by a negative control involving only saline solution.

\subsection{Statistical Analysis}

All tests were conducted in triplicate, and the results are expressed as the mean \pm standard deviation. The means of the groups were compared by unidirectional analysis of variance (ANOVA) and then Tukey's test with GraphPad Prism software. Statistical data were considered significant at $p<0.05$.

\section{Results}

\subsection{Thermogravimetric Analysis (TGA) and Differential Scanning Calorimetry (DSC)}

The thermogravimetric curves of the studied materials are shown in Figure 1a, where all the films presented two main events of thermal degradation.
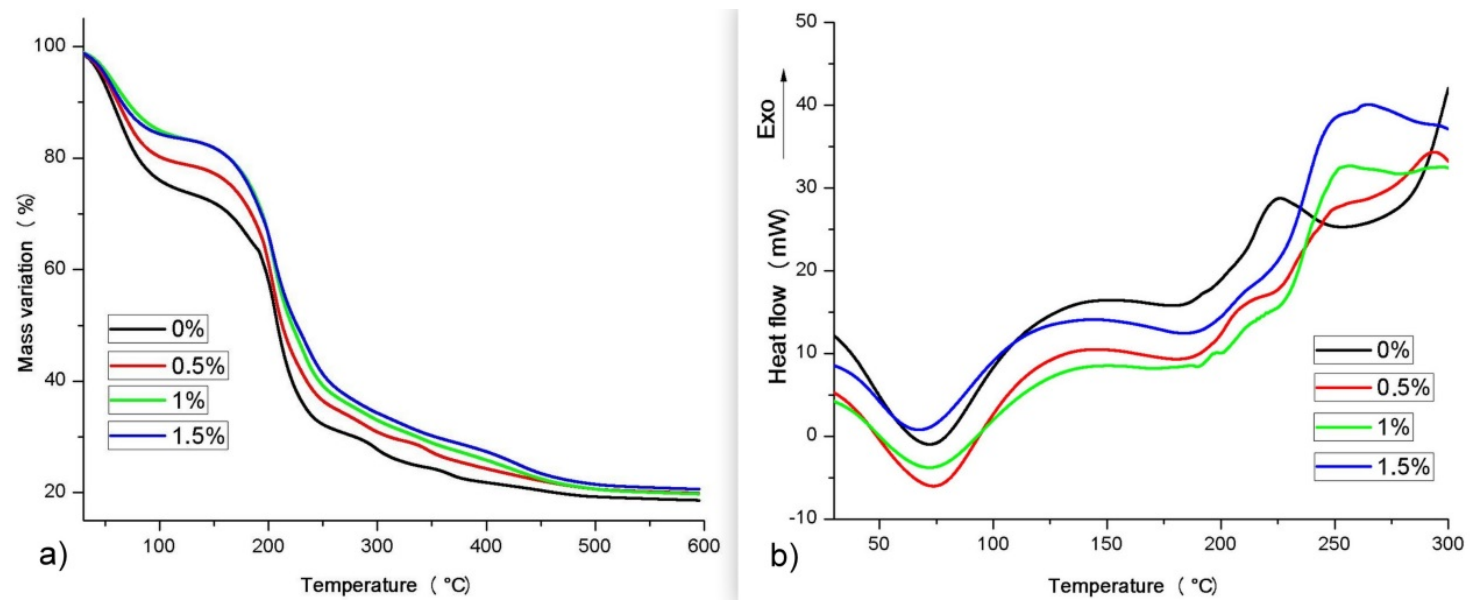

Figure 1. (a) Thermogravimetric (TG) and (b) differential scanning calorimetry (DSC) curves of the bioactive films obtained from the incorporation of cashew nut shell liquid into a sodium alginate matrix.

The first event in the TGA curves is associated with moisture loss, with values of 26.6, $21.3,16.6$, and 16.7 for films with inclusions of $0 \%, 0.5 \%, 1 \%$, and $1.5 \%$ CNSL, respectively. The second event concerns thermal degradation, and the initial temperature $\left(\mathrm{T}_{\text {onset }}\right)$ was 
similar for all films $\left(184,183,183\right.$, and $183{ }^{\circ} \mathrm{C}$ for $0 \%, 0.5 \%, 1 \%$, and $1.5 \%$, respectively). Films $0 \%, 0.5 \%, 1 \%$, and $1.5 \%$ showed temperature ranges of thermal degradation of 129 to $270{ }^{\circ} \mathrm{C}, 124$ to $269{ }^{\circ} \mathrm{C}, 126$ to $288^{\circ} \mathrm{C}$, and 120 to $294{ }^{\circ} \mathrm{C}$, respectively (Figure 1a).

Figure $1 \mathrm{~b}$ shows the DSC curves of films. The 1 st peak, at approximately $70{ }^{\circ} \mathrm{C}$, is an endothermic event relative to moisture, as also observed in the TG curves. The 2 nd peak corresponds to an exothermic event relative to the beginning of thermal degradation, with $227^{\circ} \mathrm{C}$ for $0 \% \mathrm{CNSL}$ and approximately $212{ }^{\circ} \mathrm{C}$ for the films, regardless of the CNSL inclusion. The films with CNSL showed a 3rd event, attributed to the main thermal degradation reaction, in which the inclusions of $0.5 \%, 1 \%$, and $1.5 \%$ showed values of 249,252 , and $256{ }^{\circ} \mathrm{C}$. The film with a $1.5 \%$ CNSL inclusion presented a 4 th degradation event at $264{ }^{\circ} \mathrm{C}$.

\subsection{Morphology}

The micrographs show that (Figure 2) the treatment without the addition of CNSL (a) presented a compact, smooth, regular microstructure, suggesting the formation of an ordered and homogeneous matrix, while the addition of CNSL (b, c, d) resulted in films that were generally similar to each other, with a slightly rougher surface than that in the treatment without oil inclusion (a). However, the films with the addition of $0.5 \%$ and $1 \%$ remained intact, with a sealed surface and no pores, while the incorporation of $1.5 \%$ CNSL (d) resulted in a film with the presence of cracks, indicating that this concentration made the film more brittle.
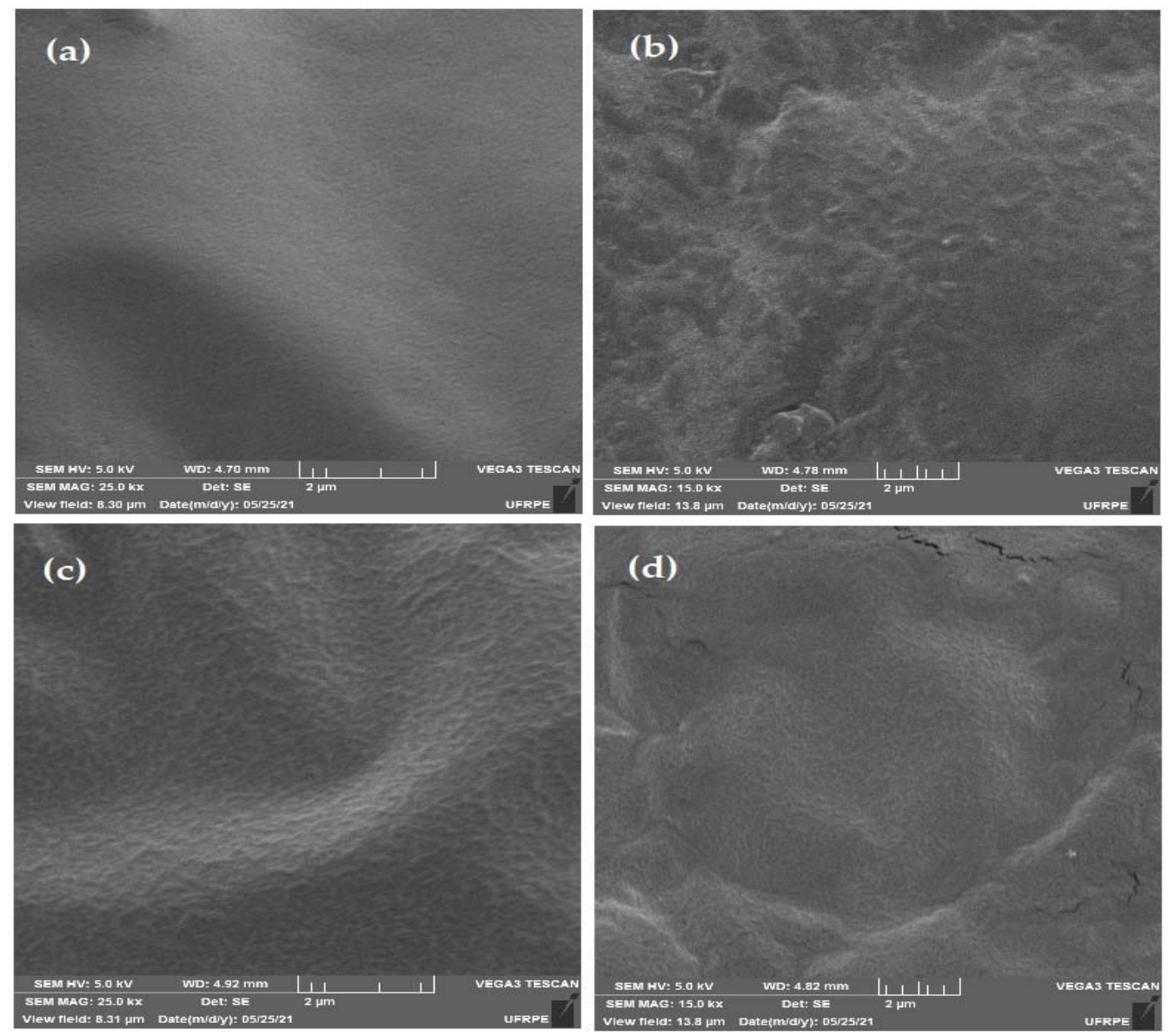

Figure 2. Surface microstructure of biopolymeric films enriched with different levels of cashew nut shell liquid (CNSL), including $0.5 \%(\mathbf{b}), 1 \%(\mathbf{c})$, and $1.5 \%(\mathbf{d})$, in alginate matrix. Saline control (a). 


\subsection{Color Parameters, Mechanical Proprieties, Water Vapor Permeability, and Thickness}

With the analysis of the color of the presented films and the measure to which the concentrations of the CNSL increased in the films, we observe that the luminosity was reduced $(p<0.05)$, and the colors red, yellow, saturation, and opacity rate were increased, where the less luminous the films are, the more opaque they are (Table 1). All the films that have been enriched with CNSL tend to move the color toward red (positive values of parameter $\mathrm{a}^{*}$ ) and yellow, and where the greater proportion of the liquid is present, the tonality is more intense. However, for the saturation index or chroma and the yellow color, the treatments with $1.0 \%$ and $1.5 \%$ CNSL inclusion did not show a difference $(p>0.05)$.

Table 1. Color parameters, mechanical properties, and water vapor permeability (WVP) of the bioactive films obtained from the incorporation of cashew nut shell liquid (CNSL) into a matrix of sodium alginate.

\begin{tabular}{|c|c|c|c|c|}
\hline \multirow{2}{*}{ Variables } & \multicolumn{4}{|c|}{ Cashew Nut Shell Liquid (\%) } \\
\hline & 0 & 0.5 & 1.0 & 1.5 \\
\hline \multicolumn{5}{|l|}{ Coloration index } \\
\hline Luminosity $\left(\mathrm{L}^{*}\right)$ & $91.59 \pm 1.02^{\mathrm{a}}$ & $80.80 \pm 1.10^{b}$ & $65.83 \pm 3.95^{\mathrm{d}}$ & $61.57 \pm 2.02^{c}$ \\
\hline Redness $\left(a^{*}\right)$ & $-1.10 \pm 0.14^{\mathrm{d}}$ & $1.61 \pm 0.24^{\mathrm{c}}$ & $6.73 \pm 0.67^{\mathrm{b}}$ & $9.34 \pm 0.45^{\mathrm{a}}$ \\
\hline Yelowness $\left(\mathrm{b}^{*}\right)$ & $7.01 \pm 0.96^{\mathrm{c}}$ & $16.9 \pm 0.69^{b}$ & $24.00 \pm 0.61^{\mathrm{a}}$ & $24.03 \pm 0.23^{a}$ \\
\hline Chroma $\left(C^{*}\right)$ & $7.09 \pm 0.97^{c}$ & $17.07 \pm 0.70^{b}$ & $24.76 \pm 0.63^{\mathrm{a}}$ & $25.75 \pm 0.31^{\mathrm{a}}$ \\
\hline Opaciy & $13.89 \pm 0.34^{\mathrm{d}}$ & $15.84 \pm 0.91^{\mathrm{c}}$ & $18.12 \pm 0.75^{b}$ & $20.10 \pm 0.98^{a}$ \\
\hline \multicolumn{5}{|l|}{ Mechanical properties } \\
\hline Thickness (mm) & $0.090 \pm 0.02^{b}$ & $0.133 \pm 0.04^{\mathrm{a}}$ & $0.238 \pm 0.04^{\mathrm{a}}$ & $0.263 \pm 0.02^{\mathrm{a}}$ \\
\hline Tensile strength $(\mathrm{MPa})$ & $54.71 \pm 0.20^{\mathrm{a}}$ & $41.54 \pm 0.08^{c}$ & $44.03 \pm 0.07^{b}$ & $36.58 \pm 0.07^{\mathrm{d}}$ \\
\hline Modulus of elasticity (MPa) & $95.75 \pm 0.36^{\mathrm{a}}$ & $72.70 \pm 0.14^{\mathrm{c}}$ & $77.04 \pm 0.12^{b}$ & $64.01 \pm 0.13^{d}$ \\
\hline Elongation at break (\%) & $42.26 \pm 3.94^{b}$ & $38.23 \pm 2.94^{b}$ & $49.78 \pm 4.67^{\mathrm{a}}$ & $51.07 \pm 1.88^{\mathrm{a}}$ \\
\hline WVP $\left.\left[10^{-10} \text { g.(m.s.Pa }\right)^{-1}\right]$ & $7.16 \pm 0.30^{c}$ & $9.11 \pm 0.19^{\mathrm{b}}$ & $29.12 \pm 7.11^{\mathrm{a}}$ & $31.02 \pm 3.24^{\mathrm{a}}$ \\
\hline
\end{tabular}

Mean \pm standard deviation, ${ }^{\mathrm{a}-\mathrm{d}}$ means followed by different lowercase letters differ by the Tukey test $(p<0.05)$.

The permeability increased as the level of CNSL increased $(p<0.05)$, especially for the concentrations of $1 \%$ and $1.5 \%$ CNSL, between which no significant difference was observed ( $p>0.05)$. Regarding the mechanical properties of the films, the maximum tensile strength of the films decreased proportionally due to the addition of CNSL $(p<0.05)$, while the addition improved $(p<0.05)$ the elasticity of the films. Regarding film thickness, the inclusion of CNSL increased $(p<0.05)$ in proportion to the level of CNSL inclusion compared to that of the treatment without inclusion.

\subsection{Antimicrobial Activity}

The results shown in Table 2 regarding the antimicrobial activity of the CNSL included in the films reveal that the CNSL presents antimicrobial activity for all the strains tested (S. typhimurium; E. coli; P. aeruginosa; L. monocytogenes; B. cereus; and S. aureus).

Table 2. Antimicrobial activity of bioactive films obtained from the incorporation of cashew nut shell liquid (CNSL) into a matrix of sodium alginate expressed as minimum inhibitory concentration (MIC) and minimum bactericidal concentration (MBC).

\begin{tabular}{ccccc}
\hline \multirow{2}{*}{ Strains } & \multicolumn{2}{c}{ Cashew Nut Shell Liquid $(\mu \mathrm{g} / \mathrm{mL})$} & \multicolumn{2}{c}{ Azithromycin $(\mu \mathrm{g} / \mathrm{mL})$} \\
\cline { 2 - 5 } & MIC & MBC & MIC & MBC \\
\hline S. typhimurium & 128 & 256 & 2 & 4 \\
E. coli & 512 & nd & 32 & 16 \\
P. aeruginosa & 128 & 256 & 8 & 16 \\
L. monocytogenes & 128 & 256 & 8 & 16 \\
B. cereus & 128 & 256 & 4 & 16 \\
S. aureus & 32 & 64 & 8 & 8 \\
\hline
\end{tabular}

nd Not determined. 
When incorporated in the filmogenic solution (FS), the CNSL presented antimicrobial activity at inclusion in $1 \%$ of the films for the strains of $P$. aeruginosa, L. monocytogenes, $B$. cereus, and $S$. aureus, with no antimicrobial activity for the strains of S. typhimurium and E. coli, as described in Table 3. Furthermore, there was also a saturation of the effectiveness at the level of $1 \%$, and as the level increased to $1.5 \%$, there was no greater effectiveness in the elimination or control of the microorganisms.

Table 3. Antimicrobial activity of bioactive films obtained from the incorporation of cashew nut shell liquid (CNSL) into a matrix of sodium alginate in different concentrations using the well diffusion agar method expressed as inhibition area diameter $(\mathrm{mm})$.

\begin{tabular}{|c|c|c|c|c|c|c|}
\hline \multirow{2}{*}{ Microorganisms } & \multicolumn{4}{|c|}{ Filmogenic Solutions (CNSL) } & \multicolumn{2}{|c|}{ Controls } \\
\hline & $0 \%$ & $0.5 \%$ & $1.0 \%$ & $1.5 \%$ & Azithromycin & Water \\
\hline S. typhimurium & $\mathrm{NI}$ & NI & $\mathrm{NI}$ & NI & $21.6 \pm 0.57$ & NI \\
\hline E. coli & NI & NI & NI & NI & $16.3 \pm 0.57$ & NI \\
\hline P. aeruginosa & $\mathrm{NI}$ & NI & $7.3 \pm 1.15^{c}$ & $10.6 \pm 0.57^{b}$ & $18.3 \pm 0.57^{\mathrm{a}}$ & NI \\
\hline L. monocytogenes & NI & NI & $7.5 \pm 0.50^{c}$ & $11.5 \pm 0.50^{b}$ & $18.5 \pm 0.50^{a}$ & NI \\
\hline B. cereus & $\mathrm{NI}$ & NI & $6.5 \pm 0.50^{b}$ & $7.6 \pm 0.5^{b}$ & $18.6 \pm 0.57^{\mathrm{a}}$ & NI \\
\hline S. aureus & $\mathrm{NI}$ & NI & $9.6 \pm 0.57^{\mathrm{c}}$ & $11.3 \pm 0.57^{b}$ & $20.3 \pm 0.57^{\mathrm{a}}$ & NI \\
\hline
\end{tabular}

$\mathrm{NI}=$ Not identified; Mean \pm standard deviation, ${ }^{\text {a-d }}$ means followed by different lowercase letters differ by the Tukey test $(p<0.05)$.

Therefore, the antimicrobial activity of FS was indicated to be less efficient than the antimicrobial activity of technical CNSL without incorporation, especially for Gramnegative bacteria.

\subsection{Antioxidant Activity}

The CNSL showed potent antioxidant activity when compared to the control treatments $(p<0.05)$ according to three different evaluation methods (Table 4).

Table 4. Antioxidant activity expressed as the $\mathrm{IC}_{50}(\mu \mathrm{g} / \mathrm{mL})$ of cashew nut shell liquid (CNSL).

\begin{tabular}{cccc}
\hline Sample & DPPH & ABTS & TAC \\
\hline CNSL & $132.89 \pm 0.27^{\mathrm{a}}$ & $102.38 \pm 0.31^{\mathrm{b}}$ & $1482.81 \pm 0.44^{\mathrm{b}}$ \\
Trolox & $28.13 \pm 0.11^{\mathrm{b}}$ & $153.67 \pm 0.02^{\mathrm{a}}$ & N.T. \\
Ascorbic acid & N.T. & N.T. & $50000 \pm 0.01^{\mathrm{a}}$ \\
\hline
\end{tabular}

Mean \pm standard deviation $(n=3),{ }^{\mathrm{a}, \mathrm{b}}$ means followed by different lowercase letters differ by the Tukey test $(p<0.05)$. DPPH: 2,2-Diphenyl-1-picryl-hydrazyl radical; ABTS: 2',2-Azino-bis(3-ethylbenzothiazoline-6sulfonate) radical; TAC: total antioxidant capacity; N.T.: not tested.

Regarding the antioxidant activity of CNSL-enriched alginate films, the inclusion of oil significantly increased $(p<0.05)$ the antioxidant activity of the films, with a DPPH elimination capacity of $0 \%$ without CNSL, $45 \%$ with the inclusion of $0.5 \%$ CNSL, and $71.4 \%$ in treatments with $1.0 \%$ and $1.5 \%$ of CNSL. There was no difference in DPPH elimination capacity between the $1.0 \%$ and $1.5 \%$ levels of CNSL inclusion (Figure 3).

\subsection{Toxicity Test}

Based on the number of live nauplii in ecotoxicity tests, it was possible to observe that the inclusion of CNSL up to $1.5 \%$ in biopolymer films to replace conventional packaging does not present health risks considering that, after $24 \mathrm{~h}$, the number of live nauplii was greater than $70 \%$ at all concentrations studied and that after $48 \mathrm{~h}$, more than $50 \%$ of nauplii remained alive, confirming the nontoxicity, as shown in Figure 4. 


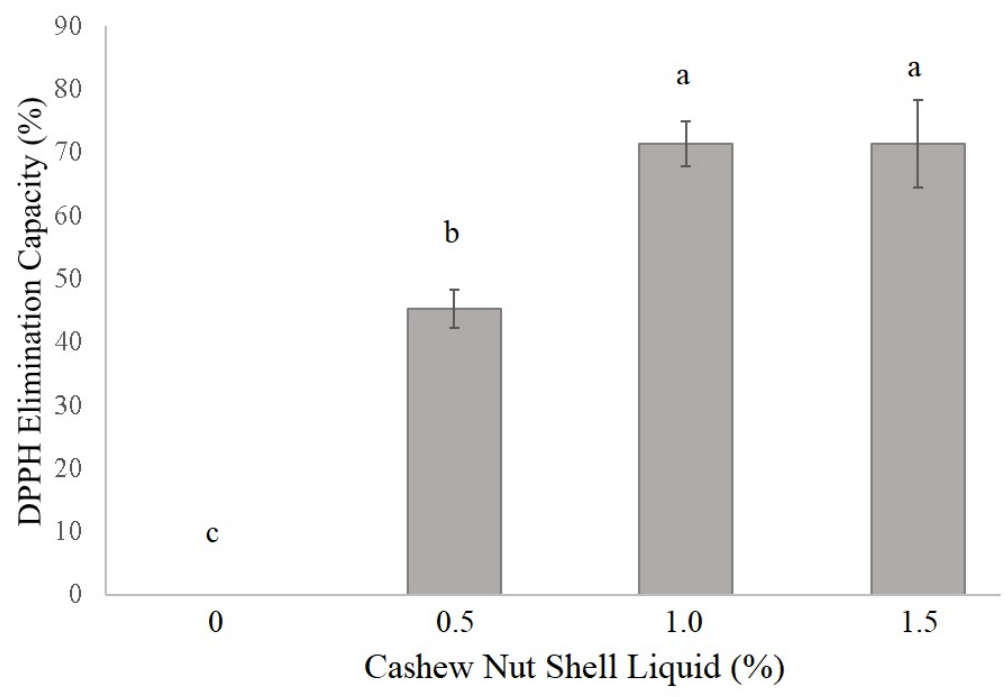

Figure 3. Antioxidant activity (elimination capacity of DPPH) of bioactive films obtained from the incorporation of cashew nut shell liquid (CNSL) into a matrix of sodium alginate. Mean \pm standard deviation $(n=3),{ }^{a-c}$ means followed by different lowercase letters differ by the Tukey test $(p<0.05)$.

a)

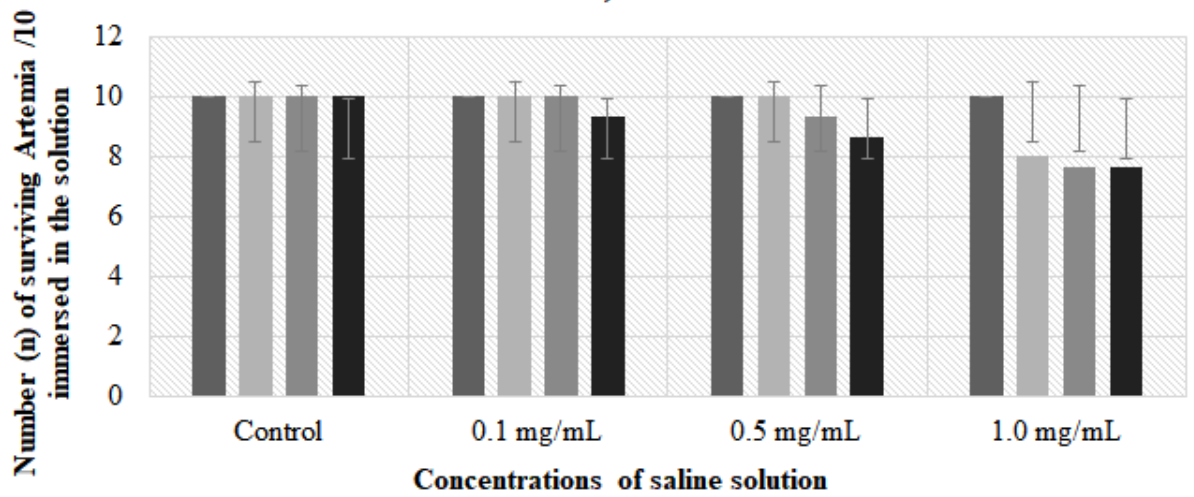

$\square 0 \% \mathrm{CNSL}=0.5 \% \mathrm{CNSL} \quad \square 1.0 \% \mathrm{CNSL} \quad \square 1.5 \% \mathrm{CNSL}$

b)

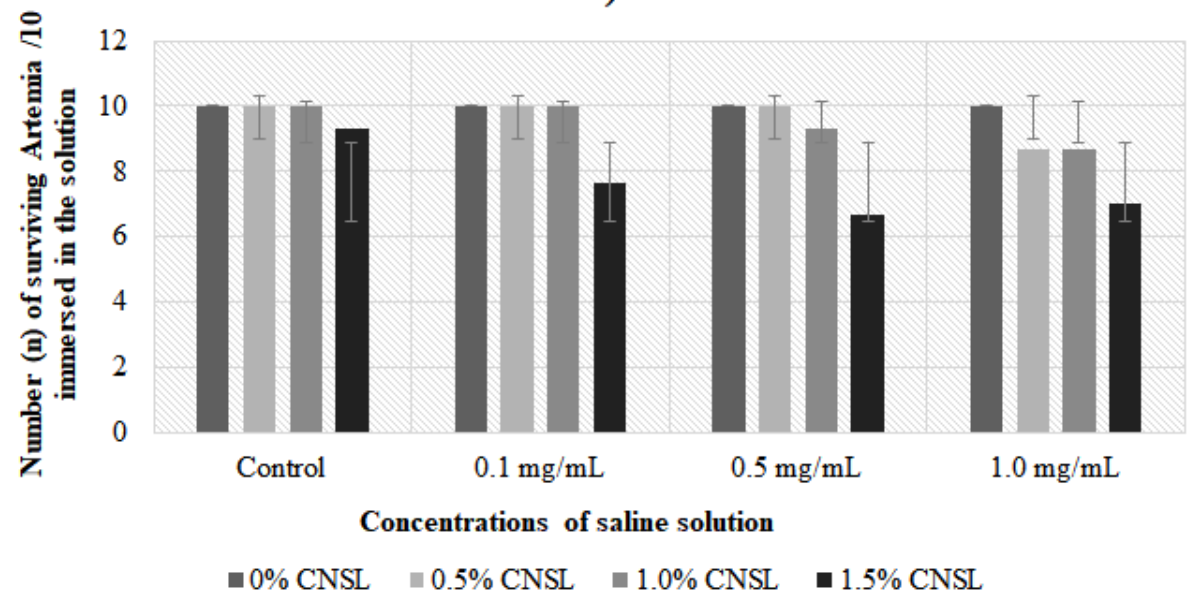

Figure 4. Determination of Artemia larva $(n=10)$ ecotoxicity in different salt concentrations from films enriched by different concentrations of cashew nut shell liquid (CNSL) after 24 (a) and $48 \mathrm{~h}$ (b). Values are described as the mean \pm standard deviation $(n=3) ; \mathrm{SEM}=$ standard error of the mean; difference by the Tukey test when $p<0.05$. 


\section{Discussion}

In addition to the material for the production of biodegradable films, several parameters need to be considered, such as their thermal degradation [24], which varies according to the composition of each film [25]. The thermal resistance proportionally improved with the addition of CNSL, considering that the oil possesses a chemical structure capable of resisting high initial degradation temperatures, especially due to the presence of aromatic rings. Furthermore, due to its high flame resistance, CNSL has the capacity to improve the thermal resistance of other polymers and is an important characteristic for food films/packaging $[26,27]$. Considering that the moisture content decreases as the CNSL content increases, increased CNSL contributes to a higher hydrophobicity and greater microbiological stability. Prasad and Pillai [28] also observed that the high presence of cardanol as a prepolymer improves the thermal stability of other polymers. This phenomenon was also observed by Menon et al. [29], where the inclusion of CNSL improved the thermal stability of the natural polymer studied. The thermal degradation of the film without the addition of CNSL is within acceptable levels in the literature, with an initial thermal temperature similar to that found by Yang et al. [30]. Although the films with CNSL had similar initial degradation temperatures $\left(\mathrm{T}_{\text {onset }}\right), \mathrm{TG}$ curves indicated that the higher the level of CNSL, the better the thermal stability of the respective film, given the decrease in the rate of thermal degradation, while DSC curves confirmed that the thermal stability of the films was directly proportional to the CNSL level. In particular, the inclusion of $1.5 \%$ CNSL produced a 3rd thermal degradation reaction in addition to two events in the other films, corroborating the better thermal stability of the film with $1.5 \%$ CNSL.

The color parameter of the film is also an extremely important characteristic and can increase the likelihood of acceptance by consumers [31]. The linear increase in the red values $\left(\mathrm{a}^{*}\right)$ and chroma $\left(\mathrm{c}^{*}\right)$ obtained in the enriched films is due to the reddish-brown coloration attributed to CNSL during its polymerization process, a result of the presence of cardol [32].

The linear increase in the $\mathrm{a}^{*}$ and $\mathrm{b}^{*}$ indexes as the CNSL level was increased caused the increased opacity of the films and, consequently, the decreased luminosity, considering that as they become darker, their opacity increases [33]. This effect is positive from the point of view of food conservation since opaque films are a barrier to light and the oxidative deterioration induced by it when applied to food, thus helping to avoid the loss of nutrients and discoloration as well as preventing unpleasant flavors from being imparted to the food product [8]. However, transparency is an important aspect from a commercial point of view to provide a better presentation and visualization of the quality of the product [34]. The increase in the opacity in films with the incorporation of the oil occurs because the oil droplets are distributed throughout the polymeric matrix, providing the dispersion of light [35].

Another very important aspect to be analyzed is the morphological aspects used to assess the structure of films, such as homogeneity and the presence of pores, cracks, voids, and imperfections [36], which directly impact the potential for food conservation. The films based on sodium alginate were in perfect condition, as in the study by Galus and Lenart [37] and Aloui et al. [38], showing that this property is characteristic of films of this polymeric matrix.

The structural irregularities found in the films after the inclusion of the CNSL arose from the decrease in the homogeneity of the biopolymer matrix as a result of the addition of a lipid component with aromatic rings and hydroxyl groups that were naturally hydrophobic, which affected the hydrophilic property of the films. This result was expected, providing imperfections and/or free spaces between the polymers and consequently affecting the increase in the passage of water vapor [35], especially in the film whose inclusion of CNSL was $1.5 \%$, where the presence of cracks confirmed that the percentage of CNSL was as high as necessary to maximize its beneficial properties and therefore does not present food safety concerns when used as food packaging. This scenario explains the results for WVP, given that this variable increased as the oil level increased, as well as results related 
to the mechanical tests, the primary aspect to be analyzed in biodegradable films because it reflects the durability of films and their ability to preserve the integrity of food [39]. The tensile strength decreased proportionally due to the addition of CNSL, mainly for the treatment with the addition of $1.5 \%$ CNSL, because the addition of CNSL, as a hydrophobic agent, to hydrophilic film, causes the film to show irregular structures, thus helping the formation of films with less chain mobility and, as a consequence, less resistance to rupture [40]. The addition of oil, in turn, can increase the flexibility and mobility/elongation of the films [41], as observed in this study.

These results corroborate other studies carried out by Han et al. [41] and Ahmed et al. [42], where the inclusion of an essential oil, such as a hydrophobic substance, hampered the intermolecular interaction process between the polymer chains, resulting in fewer tensile-resistant and plastic materials, leading to increased mobility and flexibility of the films.

For food application purposes, the increase in this WVP is not preferable, considering that the best films are those that present low water vapor permeability [33]. This capability is essential since it establishes the capacity of interaction between the films and water, protecting foods against dehydration or rehydration and thus may reduce the deterioration of food and consequently increase its shelf life [8].

The increase in film thickness by the inclusion of CNSL is justified, as the addition of oil has led to an increase in the solid content of the films, thus increasing their thickness in comparison to $0 \%$ CNSL [43]. Thus, we believe that the added hydrophobic substance becomes attached in the form of microparticles in the polymeric matrix, with a decrease in density and, consequently, an increase in thickness [44]. The inclusion of a hydrophobic substance also favored an increase in the thickness of films based on sodium alginate, as described by Mahcene et al. [45], highlighting, however, that film thickness is directly related to composition [46] as well as the method of preparation and drying conditions [37].

CNSL showed an antimicrobial effect for all strains tested in this study. However, the efficiency of the antimicrobial action of CNSL in the biofilms occurred only from its inclusion at $1 \%$. Therefore, two justifying hypotheses were developed: the first hypothesis was that part of the oil's properties may have evaporated in the film preparation stage, which requires drying at $45^{\circ} \mathrm{C}$ for $24 \mathrm{~h}$, and the second hypothesis was related to the type of CNSL used (technical), bearing in mind that even though cardanol presents antimicrobial activity, its efficiency is considerably inferior to the efficiency of anacardic acids, a major component of CNSL in nature [47]. Anacardic acid is mainly responsible for most of the antimicrobial properties [48]; thus, a greater quantity of the compound is necessary to preserve its activity in the films by means of cardanol and cardol. The sodium alginatebased film had no antimicrobial function against the tested pathogens, corroborating the studies by Han et al. [41] and Ngo et al. [49].

Furthermore, the technical CNSL evidenced promising antioxidant activity that held up after incorporation into bioactive films, as the inclusion level increased due to the presence of phenolic lipid compounds with long and unsaturated chains. The presence of aromatic rings in the CNSL affords film antioxidant properties; unsaturation within the long side chain of cardanol can be a valuable factor in the capture of free radicals [13] because these substances act as oxygen donors for peroxyl radicals, making the free radical reaction impossible [50]. However, the antioxidant activity of CNSL is not only due to the presence of cardanol but also cardol and anacardic acid [51]. This characteristic is very important because by acting as a free radical eliminator and hydrogen donor, as is the case with most of the active compounds of natural antioxidants, there is an inhibition of the generation and propagation of reactive species and free radicals [52]. Corroborating these results, several studies indicate that the inclusion of additives endowed with phenolic compounds, such as functional and/or essential oils, promotes a significant improvement in the antioxidant activity of biopolymeric films [38,53,54].

The greater efficiency of the application of antioxidant packaging concerns foods with high fat content [38], as it delays lipid oxidation, which is the main cause of food deterio- 
ration, especially of the most perishable foods, and may directly affect their organoleptic qualities, such as color, flavor, and odor [39]. Oxidative reactions are responsible for reducing the nutritional value of foods through the degradation of essential fatty acids, proteins, and liposoluble vitamins, producing strange flavors and odors and promoting changes in food color due to pigment degradation [55].

Finally, the films developed in this study were nontoxic for the levels tested, which was expected because, in addition to the percentage incorporation being low, the CNSL used was technical grade, obtained by the processing and heating of the nuts at $180-200{ }^{\circ} \mathrm{C}$, where anacardic acid suffers a decarboxylation reaction in which it is converted to cardanol [56] and becomes nontoxic. In addition, anacardic acid is responsible for the caustic, irritant, and toxic properties of the CNSL [57]. Cardanol is nontoxic [18]. Nevertheless, cardol, a compound present at a small concentration in CNSL $(10 \%)$, shows a structure similar to that of anacardic acids, as it presents a second hydroxyl in the aromatic ring and is considered to have toxic properties in some studies [58], justifying the performance of the test in this study.

\section{Conclusions}

The inclusion of CNSL in the production of biopolymeric films based on sodium alginate proved to be a promising option for use in the food industry, especially due to its high antioxidant activity, which is maintained after inclusion in biopolymeric films, and its antimicrobial activity, evidenced by the inclusion of $1 \%$ CNSL. Additionally, the inclusion of CNSL is a sustainable option and can be used in the agrifood industry to replace nondegradable food packaging while improving the quality and increasing the shelf life of perishable food. Thus, we recommend the use of film with a CNSL inclusion of $1 \%$, considering that this level of inclusion presented the best results in most of the analyses, with greater stability compared to that resulting from the $1.5 \%$ inclusion due to the increase in saturation level.

Author Contributions: Data curation, L.V. and M.d.S.; Formal analysis, L.V., E.S.F. and A.S.; Investigation, L.V., M.d.S., J.d.O. and S.E.M.; Methodology, M.d.S., R.L.O. and L.B.; Project administration, L.B.; Resources, A.S. and S.E.M.; Software, E.S.F. and A.S.; Validation, J.d.O.; Visualization, E.S.P., S.E.M. and R.L.O.; Writing-review and editing, L.B. All authors have read and agreed to the published version of the manuscript.

Funding: This research was supported by the National Council for Scientific and Technological Development (Brazil).

Institutional Review Board Statement: Not applicable.

Informed Consent Statement: Not applicable.

Data Availability Statement: The data presented in this study are available in article.

Acknowledgments: At the Coordination for the Improvement of Greater Education Personnel, and the Federal university of Campina Grande.

Conflicts of Interest: The authors declare no conflict of interest.

\section{References}

1. Popović, S.Z.; Lazić, V.L.; Hromiš, N.M.; Šuput, D.Z.; Bulut, S.N. Biopolymer Packaging Materials for Food Shelf-Life Prolongation. Biopolym. Food Des. 2015, 8, 223-277. [CrossRef]

2. Otoni, C.G.; Avena-Bustillos, R.J.; Azeredo, H.M.C.; Lorevice, M.V.; Moura, M.R.; Mattoso, L.H.C.; McHugh, T.H. Recent Advances on Edible Films Based on Fruits and Vegetables-A Review. Compr. Rev. Food Sci. Food Saf. 2017, 16, 1151-1169. [CrossRef] [PubMed]

3. Baschetti, M.G.; Minelli, M. Test methods for the characterization of gas and vapor permeability in polymers for food packaging application: A review. Polym. Test. 2020, 89, 106606. [CrossRef]

4. Muller, J.; González-Martínez, C.; Chiralt, A. Combination of Poly(lactic) Acid and Starch for Biodegradable Food Packaging. Materials 2017, 10, 952. [CrossRef] [PubMed] 
5. Cox, K.D.; Covernton, G.A.; Davies, H.L.; Dower, J.F.; Juanes, F.; Dudas, S.E. Human Consumption of Microplastics. Environ. Sci. Technol. 2019, 53, 7068-7074. [CrossRef]

6. Khodaei, D.; Álvarez, C.; Mullen, A.M. Biodegradable Packaging Materials from Animal Processing Co-Products and Wastes: An Overview. Polymers 2021, 13, 2561. [CrossRef] [PubMed]

7. Menossi, M.; Cisneros, M.; Alvarez, V.A.; Casalongué, C. Current and emerging biodegradable mulch films based on polysaccharide bio-composites. A review. Agron. Sustain. Dev. 2021, 41, 53. [CrossRef]

8. Souza, M.P.; Vaz, A.F.M.; Silva, H.D.; Cerqueira, M.A.; Vicente, A.A.; Carneiro-da-Cunha, M.G. Development and Characterization of an Active Chitosan-Based Film Containing Quercetin. Food Bioprocess Technol. 2015, 8, 2183-2191. [CrossRef]

9. Lim, C.; Yusoff, S.; Ng, C.G.; Lim, P.E.; Ching, Y.C. Bioplastic made from seaweed polysaccharides with green production methods J. Environ. Chem. Eng. 2021, 9, 105895. [CrossRef]

10. Mohamed, S.A.A.; El-Sakhawy, M.; El-Sakhawy, M.A.M. Polysaccharides, protein and lipid- Based Natural Edible Films in Food Packaging: A Review. Carbohydr. Polym. 2020, 116178. [CrossRef]

11. Umaraw, P.; Munekata, P.E.S.; Verma, A.K.; Barba, F.J.; Singh, V.P.; Kumar, P.; Lorenzo, J.M. Edible films/coating with tailored properties for active packaging of meat, fish and derived products. Trends Food Sci. Technol. 2020, 98, 10-24. [CrossRef]

12. Rodrigues, F.M.G.; Souza, A.G.; Santos, I.M.G.; Bicudo, T.C.; Silva, M.C.D.; Sinfrônio, F.S.M.; Vasconselos, A.F.F. Antioxidative properties of hydrogenated cardanol for cotton biodiesel by PDSC and UV/VIS. J. Therm. Anal. Calorim. 2009, 97, 605-609. [CrossRef]

13. Rodrigues, F.H.A.; Feitosa, J.P.A.; Ricardo, N.M.P.S.; de França, F.C.F.; Carioca, J.O.B. Antioxidant activity of cashew nut shell liquid (CNSL) derivatives on the thermal oxidation of synthetic cis-1,4-polyisoprene. J. Braz. Chem. Soc. 2006, 17, 265-271. [CrossRef]

14. Citó, A.M.D.G.L.; da Silva, J.; Saffi, J.; Richter, M.F.; Ferraz, A.D.B.F. Antioxidant properties and chemical composition of technical Cashew Nut Shell Liquid (tCNSL). Food Chem. 2011, 126, 1044-1048. [CrossRef]

15. Topuz, F.; Uyar, T. Antioxidant, Antibacterial and Antifungal Electrospun Nanofibers for Food Packaging Applications. Food Res. Int. J. 2019, 130, 108927. [CrossRef]

16. Oussalah, M.; Caillet, S.; Salmiéri, S.; Saucier, L.; Lacroix, M. Antimicrobial Effects of Alginate-Based Film Containing Essential Oils for the Preservation of Whole Beef Muscle. J. Food Prot. 2006, 69, 2364-2369. [CrossRef] [PubMed]

17. Boccard, R.; Buchter, L.; Casteels, E.; Cosentino, E.; Dransfield, E.; Hood, D.E.; Joseph, R.L.; McDougall, D.B.; Touraille, C. Procedures for measuring meat quality characteristics in beef production experiments. Report of a working group in the Commission of the European Communities (CEC) Beef Production Research Programme. Livest. Prod. Sci. 1981, 8, 385-397. [CrossRef]

18. ASTM-American Society for Testing and Material. ASTM D882- 12: Standard Test Method for Tensile Properties of Thin Plastic Sheeting; ASTM: West Conshohocken, PA, USA, 2016.

19. CLSI. Performance Standards for Antimicrobial Susceptibility Testing, 28th ed.; Clinical Laboratory Standards Institute: Wayne, PA, USA, 2018.

20. Blois, M.S. Antioxidant Determinations by the Use of a Stable Free Radical. Nature 1958, 181, 1199-1200. [CrossRef]

21. Re, R.; Pellegrini, N.; Proteggente, A.; Pannala, A.; Yang, M.; Rice-Evans, C. Antioxidant activity applying an improved ABTS radical cation decolorization assay. Free Radic. Biol. Med. 1999, 26, 1231-1237. [CrossRef]

22. Prieto, P.; Pineda, M.; Aguilar, M. Spectrophotometric quantitation of antioxidant capacity through the formation of a phosphomolybdenum complex: Specific application to the determination of vitamin E. Anal. Biochem. 1999, 269, 337-341. [CrossRef]

23. Meyer, B.N.; Ferrigni, N.R.; Putnam, J.E.; Jacobsen, L.B.; Nichols, D.E.; McLaughin, J.L. Brine Shrimp: A Convenient General Bioassay for Active Plant Constituents. J. Med. Plant Res. 1982, 45, 31-34. [CrossRef]

24. Daza, L.D.; Homez-Jara, A.; Solanilla, J.F.; Váquiro, H.A. Effects of temperature, starch concentration, and plasticizer concentration on the physical properties of ulluco (Ullucus tuberosus Caldas)-based edible films. Int. J. Biol. Macromol. 2018, 120 Pt B, 1834-1845. [CrossRef]

25. Celso, F.; Mauler, R.S.; Gomes, A.S. Thermal Properties of Speek-based Polymeric Films Containing Benzimidazole Derivatives and Fosfotungstic Acid. Polímeros Cien. Tecnol. 2008, 18, 178-186. [CrossRef]

26. Mazzetto, S.E.; Lomonaco, D.; Mele, G. Cashew nut oil: Opportunities and challenges in the context of sustainable industrial development. Quím. Nova 2009, 32, 732-741. [CrossRef]

27. Chuayjuljit, S.; Rattanametangkool, P.; Potiyaraj, P. Preparation of cardanol-formaldehyde resins from cashew nut shell liquid for the reinforcement of natural rubber. J. Appl. Polym. Sci. 2007, 104, 1997-2002. [CrossRef]

28. Prasad, V.S.; Pillai, C.K.S. Polwtzer Science-Recent Advances, 1st ed.; Bhardwaj, S., Ed.; Allied Publ. Ltd.: New Delhi, India, 1994; Volume 2.

29. Menon, A.R.R.; Pillai, C.K.S.; Nando, G.B. Thermal degradation characteristics of natural rubber vulcanizates modified with phosphorylated cashew nut shell liquid. Polym. Degrad. Stab. 1996, 52, 265-271. [CrossRef]

30. Yang, M.; Wang, L.; Xia, Y. Ammonium persulphate induced synthesis of polymethyl methacrylate grafted sodium alginate composite films with high strength for food packaging. Int. J. Biol. Macromol. 2019, 124, 1238-1245. [CrossRef]

31. Nawab, A.; Alam, F.; Haq, M.A.; Lutfi, Z.; Hasnain, A. Mango kernel starch-gum composite films: Physical, mechanical and barrier properties. Int. J. Biol. Macromol. 2017, 98, 869-876. [CrossRef] [PubMed]

32. Wasserman, D.; Dawson, C.R. Cashew nut shell liquid. III. The cardol component of Indian cashew nut shell liquid with reference to the liquid s vesicant activity. J. Am. Chem. Soc. 1948, 70, 3675-3679. [CrossRef] 
33. Homez-JFara, A.; Daza, L.D.; Aguirre, D.M.; Muñoz, J.A.; Solanilla, J.F.; Váquiro, H.A. Characterization of chitosan edible films obtained with various polymer concentrations and drying temperatures. Int. J. Biol. Macromol. 2018, 113, 1233-1240. [CrossRef] [PubMed]

34. Fernandes, A.P.S.; Costa, J.B.; Soares, D.S.B.; de Moura, C.J.; de Souza, A.R.M. Application of biodegradable films produced from irradiated whey protein concentrate. Pesq. Agropec. Trop. 2015, 45, 192-199. [CrossRef]

35. Do Evangelho, J.A.; da Silva Dannenberg, G.; Biduski, B.; el Halal, S.L.M.; Kringel, D.H.; Gularte, M.A.; da Rosa Zavareze, E. Antibacterial activity, optical, mechanical, and barrier properties of corn starch films containing orange essential oil. Carbohydr. Polym. 2019, 222, 114981. [CrossRef] [PubMed]

36. Ghelejlu, S.B.; Esmaiili, M.H.; Almasi, H. Characterization of chitosan-nanoclay bionanocomposite active films containing milk thistle extract. Int. J. Biol. Macromol. 2016, 86, 613-621. [CrossRef] [PubMed]

37. Galus, S.; Lenart, A. Development and characterization of composite edible films based on sodium alginate and pectin. J. Food Eng. 2013, 115, 459-465. [CrossRef]

38. Aloui, H.; Deshmukh, A.R.; Khomlaem, C.; Kim, B.S. Novel composite films based on sodium alginate and gallnut extract with enhanced antioxidant, antimicrobial, barrier and mechanical properties. Food Hydrocoll. 2020, 113, 106508. [CrossRef]

39. Shahbazi, Y. The properties of chitosan and gelatin films incorporated with ethanolic red grape seed extract and Ziziphora clinopodioides essential oil as biodegradable materials for active food packaging. Int. J. Biol. Macromol. 2017, 99, 746-753. [CrossRef]

40. Rubilar, J.F.; Cruz, R.M.S.; Silva, H.D.; Vicente, A.A.; Khmelinskii, I.; Vieira, M.C. Physico-mechanical properties of chitosan films with carvacrol and grape seed extract. J. Food Eng. 2013, 115, 466-474. [CrossRef]

41. Han, Y.; Yu, M.; Wang, L. Physical and antimicrobial properties of sodium alginate/carboxymethyl cellulose films incorporated with cinnamon essential oil. Food Packag. Shelf Life 2018, 15, 35-42. [CrossRef]

42. Ahmed, J.; Mulla, M.Z.; Arfat, Y.A. Thermo-mechanical, structural characterization and antibacterial performance of solvent casted polylactide/cinnamon oil composite films. Food Control. 2016, 69, 196-204. [CrossRef]

43. Rambabu, K.; Bharath, G.; Banat, F.; Show, P.L.; Cocoletzi, H.H. Mango leaf extract incorporated chitosan antioxidant film for active food packaging. Int. J. Biol. Macromol. 2018, 126, 1234-1243. [CrossRef]

44. Luís, Â.; Pereira, L.; Domingues, F.; Ramos, A. Development of a carboxymethyl xylan film containing licorice essential oil with antioxidant properties to inhibit the growth of foodborne pathogens. LWT Food Sci. Technol. 2019, 111, 218-225. [CrossRef]

45. Mahcene, Z.; Khelil, A.; Hasni, S.; Akman, P.K.; Bozkurt, F.; Birech, K.; Goudjil, M.B.; Tornuk, F. Development and characterization of sodium alginate based active edible films incorporated with essential oils of some medicinal plants. Int. J. Biol. Macromol. 2019, 15, 124-132. [CrossRef] [PubMed]

46. Abugoch, L.E.; Tapia, C.; Villamán, M.C.; Yazdani-Pedram, M.; Díaz-Dosque, M. Characterization of quinoa protein-chitosan blend edible films. Food Hydrocoll. 2011, 25, 879-886. [CrossRef]

47. Himejima, M.; Kubo, I. Antibacterial agents from the cashew Anacardium occidentale (Anacardiaceae) nut shell oil. J. Agric. Food Chem. 1991, 39, 418-421. [CrossRef]

48. Branco, A.F.; Giallongo, F.; Frederick, T.; Weeks, H.; Oh, J.; Hristov, A.N. Effect of technical cashew nut shell liquid on rumen methane emission and lactation performance of dairy cows. J. Dairy Sci. 2015, 98, 4030-4040. [CrossRef] [PubMed]

49. Ngo, T.M.P.; Dang, T.M.Q.; Tran, T.X.; Rachtanapun, P. Effects of Zinc Oxide Nanoparticles on the Properties of Pectin/Alginate Edible Films. Int. J. Polym. Sci. 2018, 1, 1-9. [CrossRef]

50. Barreiros, A.L.B.S.; David, J.M.; David, J.P. Oxidative stress: Relations between the formation of reactive species and the organism's defense. Quím. Nova 2006, 29, 113-123. [CrossRef]

51. Voirin, C.; Caillol, S.; Sadavarte, N.V.; Tawade, B.V.; Boutevinab, B.; Wadgaonkar, P.P. Functionalization of cardanol: Towards biobased polymers and additives. Polym. Chem. 2014, 5, 3142-3162. [CrossRef]

52. Kulisic, T.; Radonic, A.; Katalinic, V.; Milos, M. Use of different methods for testing antioxidative activity of oregano essential oil. Food Chem. 2004, 85, 633-640. [CrossRef]

53. Benbettaïeb, N.; Mahfoudh, R.; Moundanga, S.; Brachais, C.H.; Chambin, O.; Debeaufort, F. Modeling of the release kinetics of phenolic acids embedded in gelatin/chitosan bioactive-packaging films: Influence of both water activity and viscosity of the food simulant on the film structure and antioxidant activity. Int. J. Biol. Macromolecules 2020, 160, 780-794. [CrossRef]

54. Estevez-Areco, S.; Guz, L.; Famá, L.; Candal, R.; Goyanes, S. Bioactive starch nanocomposite films with antioxidant activity and enhanced mechanical properties obtained by extrusion followed by thermocompression. Food Hydrocoll. 2019, 96, 518-528 [CrossRef]

55. Bastarrachea, L.J.; Wong, D.E.; Roman, M.J.; Lin, Z.; Goddard, J.M. Active packaging coatings. Coatings 2015, 5, 771-791. [CrossRef]

56. Guissoni, A.C.P.; Silva, I.G.; Geris, R.; Cunha, L.C.; Silva, H.H.G. Larvicidal activity of Anacardium occidentale as an alternative to control Aedes aegypti and its toxicity in Rattus norvegicus. Rev. Bras. Pl. Med. 2013, 15, 363-367. [CrossRef]

57. França, F.C.F.; Coelho, E.D.L.; Uchôa, A.F.J.; Rodrigues, F.H.A.; Ribeiro, M.E.N.P.; Soares, S.D.A.; Ricardo, N.M.P.S. Synthesis and characterization of alkylphenyl polyglycosidic surfactants from amylose and alkyl phenols extracted from natural CNSL. Quim. Nova 2016, 39, 771-781. [CrossRef]

58. Osmari, M.P.; Matos, L.F.; Salab, B.L.; Diaz, T.G.; Giotto, F.M. Cashew nut shell liquid: Characteristics and applicability in animal production. Arq. Bras. Med. Vet. Zootec. 2015, 9, 143-149. [CrossRef] 